\title{
Endocellular polyamine availability modulates epithelial-to-mesenchymal transition and unfolded protein response in MDCK cells
}

\author{
Marco Prunotto ${ }^{1,2,8}$, Alessandra Compagnone ${ }^{3,8}$, Maurizio Bruschi ${ }^{1,2}$, Giovanni Candiano ${ }^{1}$, \\ Sebastiano Colombatto ${ }^{3}$, Andrea Bandino ${ }^{3}$, Andrea Petretto ${ }^{4}$, Solange Moll ${ }^{5}$, Marie Luce Bochaton-Piallat ${ }^{6}$, \\ Giulio Gabbiani ${ }^{6}$, Veronica Dimuccio ${ }^{1}$, Maurizio Parola ${ }^{3}$, Lorenzo Citti ${ }^{7}$ and GianMarco Ghiggeri ${ }^{1}$
}

Epithelial-to-mesenchymal transition (EMT) is involved in embryonic development as well as in several pathological conditions. Literature indicates that polyamine availability may affect transcription of c-myc, matrix metalloproteinase (MMP)1, MMP2, TGF $\beta_{1}$, and collagen type I mRNA. The aim of this study was to elucidate polyamines role in EMT in vitro. Madin-Darby canine kidney (MDCK) cells were subjected to experimental manipulation of intracellular levels of polyamines. Acquisition of mesenchymal phenotype was evaluated by means of immunofluorescence, western blots, and zymograms. MDCK cells were then subjected to $2 \mathrm{D}$ gel proteomic study and incorporation of a biotinilated polyamine (BPA). Polyamine endocellular availability modulated EMT process. Polyamine-depleted cells treated with TGF $\beta_{1}$ showed enhanced EMT with a marked decrease of E-cadherin expression at plasma membrane level and an increased expression of mesenchymal markers such as fibronectin and $\alpha$-smooth muscle actin. Polyamine-depleted cells showed a twofold increased expression of the rough endoplasmic reticulum (ER)-stress proteins GRP78, GRP94, and HSP90 $\alpha / \beta$ in $2 D$ gels. The latter data were confirmed by western blot analysis. Administration of BPA showed that polyamines are covalently linked, within the cell, to ER-stress proteins. Intracellular polyamine availability affects EMT in MDCK cells possibly through the modulation of ER-stress protein homeostasis.

Laboratory Investigation (2010) 90, 929-939; doi:10.1038/labinvest.2010.65; published online 8 March 2010

KEYWORDS: MDCK; polyamines; EMT; UPR; DFMO; ER-stress

Epithelial-mesenchymal transition (EMT), paradigmatic of the cell plasticity concept, is involved in embryonic development as well as in several pathological conditions, including organ fibrosis and cancer progression. ${ }^{1}$ During EMT, epithelial cells loose polarization, disassemble cell-cell junctions, and switch to a mesenchymal-type gene expression program. Cells undergoing EMT start to synthesize fibronectin, collagen type I, and vimentin acquiring a fibroblast-like phenotype. In some cases, cells undergoing EMT express $\alpha$-smooth muscle actin ( $\alpha$-SMA) assuming the myofibroblastic phenotype. Several signaling factors, including TGF $\beta_{1}$, trigger this process. ${ }^{1-3}$

It has been shown that TGF $\beta_{1}$ downregulates the spermidine synthase gene $e^{4}$ and that fibroblasts treated with difluoromethylornithine (DFMO), a specific inhibitor of the enzyme ornithine decarboxylase (ODC), responsible in mammalian cells of ornithine decarboxylation to putrescine, exhibit a significant increase in c-myc, matrix metalloproteinase (MMP)1, MMP2, TGF $\beta_{1}$, and collagen type I mRNAs, ${ }^{5}$ suggesting that intracellular polyamine levels affects transcription of EMT-related genes.

Polyamines are organic polycations present in all living organisms. Higher polyamines are synthesized by the sequential addition of aminopropyl groups to putrescine by a reaction involving $S$-adenosyl methionine decarboxylase (SAMDC) as well as spermidine and spermine synthases. ODC and SAMDC are considered rate-limiting enzymes in polyamine biosynthesis. In addition to these multi-level

\footnotetext{
${ }^{1}$ Nephrology Laboratory, Giannina Gaslini Children's Hospital, Genoa, Italy; ${ }^{2}$ RenalChild Foundation, c/o Giannina Gaslini Children's Hospital, Genoa, Italy; ${ }^{3}$ Department of Experimental Medicine and Oncology, University of Torino, Torino, Italy; ${ }^{4}$ Mass Spectrometry Core Facility, Giannina Gaslini Children Hospital, Genoa, Italy; ${ }^{5}$ Service de Pathologie Clinique, Hôpitaux Universitaires de Genève, Geneva, Switzerland; ${ }^{6}$ Division of Pathology, Geneva University Hospital, Geneva, Switzerland and ${ }^{7}$ Department of Clinical Physiology—CNR, Pisa, Italy

Correspondence: Dr M Prunotto, PhD, Nephrology Laboratory, Giannina Gaslini Children's Hospital, Largo G. Gaslini, 5-16147 Genoa, Italy. E-mail: marco.prunotto@gmail.com

${ }^{8}$ These authors contributed equally to this work

Received 10 September 2009; revised 11 January 2010; accepted 27 January 2010
} 
controls of synthesis, uptake and efflux into extracellular environment co-operate in the fine-tuning of intracellular levels of polyamines. The availability of specific inhibitors of ODC and SAMDC has allowed to establish the essential role of polyamines in many processes, including cell growth, ${ }^{6-9}$ differentiation, ${ }^{10,11}$ cell adhesion, ${ }^{12}$ induction of apoptosis, ${ }^{13}$ and signal transduction. ${ }^{14-16}$ On this basis, DFMO administration has been suggested for the treatment of infectious diseases, ${ }^{17}$ protozoal parasitism ${ }^{18}$ or, with modest results, cancer ${ }^{19}$ and hyper proliferative diseases. ${ }^{20}$

Polyamines may act as ligands of DNA, RNA, phospholipids, nucleotide triphosphates, or proteins and act as effectors of gene expression and signal transduction. Polyamines are also substrates for transglutaminase-2 (TG-2), which catalyses the covalent incorporation of several low molecular weight amines into protein in the form of $\gamma$-carboxyl group of a peptide-bound glutamic acid. Key cellular processes are modulated by the amount of both free and protein-conjugated polyamines formed by TG activity. ${ }^{21}$

The aim of this study was to elucidate whether polyamines have a role in EMT modulation of Madin-Darby canine kidney (MDCK) cells derived from distal tubular epithelial cells.

\section{MATERIALS AND METHODS Cell Culture}

MDCK cells (ATCC, Middlesex, UK) were cultured in Dulbecco's modified Eagle medium (DMEM; Sigma, Saint-Louis, USA) and supplemented with $10 \%$ fetal bovine serum (FBS). Polyamine-related experiments were instead performed in RPMI 1640 (Gibco BRL, Paisley, UK) supplemented with $10 \%$ horse serum (HS) with cells cultured in $150 \mathrm{~cm}^{2}$ flasks. Addition of HS to all experimental conditions instead of FBS is an established procedure aimed at minimizing cytotoxic effects due to high levels of amine-oxidases in FBS, which, on the contrary, is very low in HS. Addition of HS instead of FBS is necessary because of the experimental protocol design that, in some conditions, requires addition of polyamines (i.e. to counteract effect of DFMO). FBS high-level content of amino-oxidases can in fact generate significant amounts of hydrogen peroxide, ammonia, and aldehydes through polyamine degradation, leading to cell injury and death. ${ }^{22}$ Cells were plated and pre-treated, when scheduled, alternatively with $3 \mathrm{mM}$ DFMO for $24 \mathrm{~h}$, leading to the depletion of endocellular polyamines, or DFMO + a mix of polyamines (P, containing $10 \mu \mathrm{M}$ putrescine and $10 \mu \mathrm{M}$ spermidine) to validate the specific effect of DFMO. Medium was changed after $24 \mathrm{~h}$, and cells were exposed to the following experimental conditions: control (RPMI $+10 \%$ HS), DFMO $(\mathrm{RPMI}+10 \% \mathrm{HS}+3 \mathrm{mM} \quad \mathrm{DFMO}), \quad \mathrm{TGF} \beta_{1} \quad(\mathrm{RPMI}+10 \%$ $\left.\mathrm{HS}+10 \mathrm{ng} / \mathrm{ml} \mathrm{TGF} \beta_{1}\right), \mathrm{DFMO}+\mathrm{TGF} \beta_{1}(3 \mathrm{mM} \mathrm{DMFO}$ and $10 \mathrm{ng} / \mathrm{ml} \mathrm{TGF} \beta_{1}$, respectively, in RPMI $+10 \% \mathrm{HS}$ ) or $\mathrm{DFMO}+\mathrm{TGF} \beta_{1}+\mathrm{P}\left(3 \mathrm{mM} \mathrm{DMFO}\right.$ and $10 \mathrm{ng} / \mathrm{ml} \mathrm{TGF} \beta_{1}$, respectively, plus polyamine mix, in RPMI $+10 \% \mathrm{HS}$ ). Cells were allowed to grow up to $96 \mathrm{~h}$ and processed for western blot or immunofluorescence. Cells pre-treated with $3 \mathrm{mM}$ DMFO for $24 \mathrm{~h}$ were used to evaluate proteins linked to polyamines that were assessed through the administration of $100 \mu \mathrm{M}$ EZ-link penthylamine-biotin (BPA, Pierce, Rockford, USA) for further $6 \mathrm{~h}$. Cells were then finally processed for two-dimensional (2D) electrophoresis or immunofluorescence, in this case, BPA administration was performed in the absence or presence of a specific siRNA against TG-2.

\section{Assessment of TGF $\beta_{1}$ mRNA and Protein in Polyamine-Depleted Cells}

TGF $\beta_{1}$ mRNA presence was routinely assessed through RT-PCR in control and DFMO-treated cells. TGF $\beta_{1}$ protein was evaluated with two different methods: secreted protein was evaluated on 5-day treated cells pre-treated on day 4 with Brefeldin A (Sigma-Aldrich), this to prevent cytokine secretion. Cells were then fixed, stained with an anti-TGF $\beta_{1}$ antibody (Clone TB21, Serotec GmbH, Dusseldorf, Germany) and detected with corresponding FITC-conjugated secondary antibody. Cells were then observed through a FACS Excalibur (Becton \& Dickinson, Mountain View, USA). TGF $\beta_{1}$ in the supernatant was dosed at day 5 of treatment through application of a specific ELISA test (Human TGF $\beta_{1}$ Instant ELISA, Bender MedSystems, Wien, Austria). In both cases, positive control was obtained by treatment of MDCK cells with $4.2 \mu \mathrm{M}$ Cyclosporin as described earlier by Feldman et al. ${ }^{23}$

\section{TG-2 Knockdown}

The TG-2 knockdown was performed by the administration of a specific siRNA addressed to the known incomplete canine transcript sequence (accession $\mathrm{N}^{\circ}$ DR103953) targeting a 23 nucleotide long stretch starting at 573 nucleotide. The sequences of siRNA were: CAAGCAGGCTTTAGAGCCACA AA (sense strand) and UGUGGCUCUAAAGCCUGCUUG AA (antisense strand). The two oligonucleotides were dissolved in $20 \mathrm{mM}$ Tris- $\mathrm{HCl}$ buffer, $100 \mathrm{mM} \mathrm{NaCl}, \mathrm{pH} 7.5$ and then annealed by slow cooling after 1 min denaturation in boiling water bath. The siRNA was administered to cultures in a 12-well plate at $100 \mathrm{nM}$ final concentration using a lipoplexed vehicle GeneSilencer (GenLantis, San Diego CA, USA) according to the manufacturer's instructions in serumfree medium $8 \mathrm{~h}$ later, cells were then washed and used for BPA administration experiments. As control, the siRNA addressed to fluorescent protein GFP was administered to parallel cultures. Sense strand: CAAGCUGACCCUGAAGUU CUAA; antisense strand: AGAACUUCAGGGUCAGCUUGAA.

\section{Matrix Metalloproteinase Assay}

MMP evaluation was performed at $120 \mathrm{~h}$ on extracellular medium of cells submitted exactly to the above-described experimental protocol. Medium was changed $24 \mathrm{~h}$ before medium sampling. Briefly, samples were loaded onto a standard $7.5 \%$ acrylamide gel containing $0.1 \%$ gelatin and run at $120 \mathrm{~V}$ for $2 \mathrm{~h}$. Gelatin digestion was counterstained with Coomassie Blue R-250 (Sigma-Aldrich). Zymograms 
were loaded based on cellular protein concentration as evaluated by BCA assay.

\section{Polyamine Content Evaluation}

Cells were scraped in $0.2 \mathrm{M} \mathrm{HClO}_{4}$ and subsequently centrifuged at $15000 \mathrm{~g}$. Supernatant was dansylated and analyzed by HPLC as described earlier. ${ }^{24}$ Detection was performed with a fluorimeter (Waters 2475, Waters Corporation, Watford, UK).

\section{Apoptosis Assessment in Polyamine-Depleted Cells}

Apoptosis was assessed in control and polyamine-depleted cells through Annexin V/propidium iodide labeling and subsequent FACS analysis (FACS Excalibur).

\section{D Electrophoresis and Western Blot}

Cells collected for western blot and 2D were trypsinized, counted, and washed in TBS. For western blot, $4 \times 10^{4} \mathrm{cells} / \mu \mathrm{l}$ were resuspended in Laemmli sample buffer-containing phosphatase and protease inhibitor cocktail. Samples were then boiled for $10^{\prime}$ and proteins concentration was determined using BCA assay.

Western blot samples (10-50 $\mu \mathrm{g})$ were load onto a SDSPAGE (T\% 8-16) in a Protean II XI system (Bio-Rad, Hercules, CA, USA), transferred onto nitrocellulose membrane (Protean BA, Schleicher \& Schuell, Dassel, Germany) with a Novablot semidry system, $3 \% \mathrm{w} / \mathrm{v}$ BSA saturated in TBS and incubated separately with e-cadherin (Santa Cruz Biotechnologies, CA, USA, 1:1000), fibronectin (Santa Cruz, 1:1000), $\alpha$-SMA (kindly provided by Professor G Gabbiani, 1:750), $\beta$-tubulin (AbCam, 1:1000), GRP78 (Santa Cruz Biotechnology, 1:1000), GRP94 (Sigma, 1:1000), HSP90 $\alpha / \beta$ (Santa Cruz Biotechnology, 1:1000) $\alpha$-enolase (AbD Serotec, $1: 1000$ ) or vimentin (Novocastra, $1: 1000$ ) in $3 \% \mathrm{w} / \mathrm{v}$ BSA in TBS-Tween $0.15 \% \mathrm{v} / \mathrm{v}$ (TBS-T). Membranes were then rinsed in TBS-T and incubated with corresponding secondary antibodies. Chemioluminescence was used for immunodetection. Images were digitalized by mean of VersaDoc 4000 (Bio-Rad) and analyzed with QuantityOne software (Bio-Rad).

For analytical $(100 \mu \mathrm{g})$ and preparative $(400 \mu \mathrm{g}) 2 \mathrm{D}$ electrophoresis, samples were solubilized in the reduction/ alkylation solution, ie $8 \mathrm{M}$ urea, $4 \%$ CHAPS, $5 \mathrm{mM}$ tributylphosphine, $20 \mathrm{mM}$ iodoacetamide (IAA), $40 \mathrm{mM}$ Tris, and $0.1 \mathrm{mM}$ EDTA pH 8.5. Before isoelectric focusing (IEF), samples were incubated in this solution for $3 \mathrm{~h}$, to allow proper reduction and alkylation. To prevent over alkylation during the IEF step, excess of IAA was neutralized by adding an equimolar amount of DTT. Samples were then cleaned using an ice-cool solution consisting of tri- $n$-butyl-phosphate: acetone: methanol $(1: 12: 1)$. Fourteen milliliters of this mixture were added to each sample to reach a final acetone concentration of $80 \%(\mathrm{v} / \mathrm{v})$ and incubated at $4{ }^{\circ} \mathrm{C}$ for $90^{\prime}$. The precipitate was pelleted by centrifugation at $2800 \mathrm{~g}$ for $20^{\prime}$ at $4^{\circ} \mathrm{C}$. After washing with the same de-lipidizing solution, it was centrifuged again and then air- dried. Finally, samples were dissolved in the focusing solution, ie $7 \mathrm{M}$ urea, $2 \mathrm{M}$ thiourea, 4\% CHAPS, and $50 \mathrm{mM}$ dithioerythritol (DTE) and load onto home-made non-linear $\mathrm{pH} 3-10$ strips $(18 \mathrm{~cm}$ long, $3 \mathrm{~mm}$ wide, $0.5 \mathrm{~mm}$ thick). ${ }^{25}$ Strip re-swelling was carried out overnight at room temperature in the focusing solution, ie $7 \mathrm{M}$ urea, $2 \mathrm{M}$ thiourea, $2 \%(\mathrm{w} / \mathrm{v})$ CHAPS, $15 \mathrm{mM}$ DTE, and a $0.6 \%(\mathrm{v} / \mathrm{v})$ carrier ampholyte cocktail, containing $40 \%$ of the $\mathrm{pH} 3.5-10$ and $60 \%$ of the $\mathrm{pH} 4-8$ intervals.

The proteins were focused at $\leq 50 \mathrm{~mA}$ per strip at $20^{\circ} \mathrm{C}$, using progressively increasing voltage for a total of $80000 \mathrm{Vh}$. Equilibration step was carried out for $30^{\prime}$ in the equilibration buffer, ie $6 \mathrm{M}$ Urea, $50 \mathrm{mM}$ Tris- $\mathrm{HCl} \mathrm{pH} 8.8,2 \% \mathrm{w} / \mathrm{v}$ SDS, $30 \% \mathrm{v} / \mathrm{v}$ glycerol, and $0.01 \% \mathrm{w} / \mathrm{v}$ bromophenol blue. In second dimension was used a SDS-PAGE (T\% 8-16) in a Protean II XI system (Bio-Rad).

Blue silver colloidal staining ${ }^{26}$ or silver staining were used for preparative or analytical proteins detection. Images were digitalized by mean of GS-800 (Bio-Rad) and analyzed with PDQuest software (Bio-Rad).

Procedure described above was also adopted for $2 \mathrm{D}$ western blot of BPA-labeled proteins $\left(\mathrm{BPA}^{+}\right)$. Briefly, proteins were transferred to nitrocellulose membrane, saturated in $3 \% \mathrm{w} / \mathrm{v}$ BSA in TBS, and incubated with neutravidin HRP-conjugated (Pierce Biotech., Rockford, USA) in 1\% w/v BSA in TBS-T. Chemioluminescence was used for immunodetection. Images were analyzed with PDQuest software (Bio-Rad); 2D experiments were performed in triplicate.

\section{Statistical Analysis}

Densitometric values of $2 \mathrm{D}$ gel and western blot were analyzed using non-parametric Mann-Whitney $U$ test. In the case of 2D gels, spots with at least twofold increase relative to control with corresponding two-tailed $P$-value $<0.05$ were accepted as statistically significant. Mass spectrometry identification was limited to $\mathrm{BPA}^{+}$spots retaining these characteristics. Densitometric western blot differences were considered statistically significant at two-tailed $P$-value $<0.05$.

\section{Tryptic Digestion and Protein Identification by LC-ESI MS-MS/MS}

Protein spots were excised from gel, rinse in $50 \% \mathrm{v} / \mathrm{v}$ acetonitrile (ACN) in $5 \mathrm{mM}$ ammonium bicarbonate $\mathrm{pH} 8.9$ until full destaining, rinse twice in $100 \% \mathrm{v} / \mathrm{v} \mathrm{ACN}$, and briefly rinse in $1 \mathrm{mM} \mathrm{CaCl}{ }_{2}$ and $100 \mathrm{mM}$ ammonium bicarbonate $\mathrm{pH}$ 8.9. Enzymatic digestions were performed using trypsin in $100 \mathrm{mM}$ ammonium bicarbonate buffer $\mathrm{pH} 7.8$ overnight at $37^{\circ} \mathrm{C}$. After incubation, the reaction was quenched by the addition of formic acid to $\mathrm{pH} 2$.

All mass spectrometric measurements were performed using a LTQ linear ion trap mass spectrometer (Thermo Electron, San Jose, USA) coupled to a HPLC Surveyor (Thermo Electron) and equipped with a Jupiter C18 column $250 \times 1 \mathrm{~mm}$ (Phenomenex). Peptides were eluted from the 
column using an acetonitrile gradient, 5\% B for $6^{\prime}$ followed by 5 to $90 \%$ B within $109^{\prime}$ (eluent A: $0.1 \%$ formic acid in water; eluent B: $0.1 \%$ formic acid in acetonitrile) at flow rate of $50 \mu \mathrm{l} / \mathrm{min}$. The column effluent was directed into the electro spray source. The spray voltage was $5.0 \mathrm{kV}$. The ion trap capillary was kept at $200^{\circ} \mathrm{C}$ and the voltage at $2.85 \mathrm{~V}$. Spectra were obtained in automated MS/MS mode: each full MS scan (m/z 400-1800) was followed by five MS/MS of the most abundant ions. The ions analyzed this way were automatically excluded for $30^{\prime \prime}$.

The raw data acquired by the mass spectrometer were converted in a peak list file for database search using Extract_msn in Bioworks 3.3.1 Sp1 with default parameters for LTQ spectra.

Protein identification was performed using SEQUEST software 3.3.1 from Thermo Electron, operating on a 10-processor computer cluster (AETHIA, Torino, Italia) and searched against a Canis familiaris protein database (no. of protein entries 41427) downloaded on $11 / 2008$ by NCBI using the taxonomy browser tool. Peptide MS/MS assignments were filtered following very high stringent criteria: Xcorr $\geq 1.9$ for the singly charged ions, Xcorr $\geq 2.2$ for doubly charged ions, and Xcorr $\geq 3.7$ for triply charged ions, peptide probability $\leq 0.01$, Delta $\mathrm{Cn} \geq 0.1$, and Rsp $\leq 4$ according to the HUPO criteria. ${ }^{27}$ The mass tolerance for precursor ions was set to $2 \mathrm{amu}$ and the mass tolerance for fragment ions was $1 \mathrm{amu}$. To identify the largest panel of peptides, the option no enzyme was used for the in silica digestion of human databases, so every combination of human peptides was evaluated. Moreover, the search parameters no included variable or fix modifications.

\section{Immunofluorescence Analysis}

Indirect immunofluorescence analysis was performed as described earlier. ${ }^{28}$ Briefly, cells were gently rinsed in warm $\mathrm{RPMI} / 2 \%$ HEPES buffer and fixed for $20^{\prime}$ at $37^{\circ} \mathrm{C}$ in $1 \%$ paraformaldehyde dissolved in RPMI/2\% HEPES buffer. Cells were then rinsed in PBS and stained for e-cadherin (1:100), fibronectin (1:100), zonula occludens 1 (ZO-1, 1:100), TG-2 (clone CUB 7402, Thermo Fisher Scientific, Fremont, USA), GRP78 (ABcam, Cambridge, USA) or $\alpha$-SMA (1:50). Detection was performed with corresponding Alexa 488 or Alexa 568 conjugated secondary antibody. Nuclei were counterstained with DAPI. Images were acquired on a confocal Apotome Axiovert microscope (Carl Zeiss AG, Jena, Germany).

\section{RESULTS}

\section{DFMO Administration Reduces Intracellular Polyamine Content in MDCK Cells}

DFMO administration reduces MDCK intracellular levels of polyamines (Figure 1).

DFMO administration reduced intracellular polyamine content to $\sim 20 \%$ of controls values (ie $5.922 \pm 0.296$ $\mathrm{nmol} / \mathrm{mg}$ of total protein extract in DFMO-treated cells $v s$ $29.215 \pm 1.416 \mathrm{nmol} / \mathrm{mg}$ in control cells, $P<0.001)$. TGF $\beta 1$

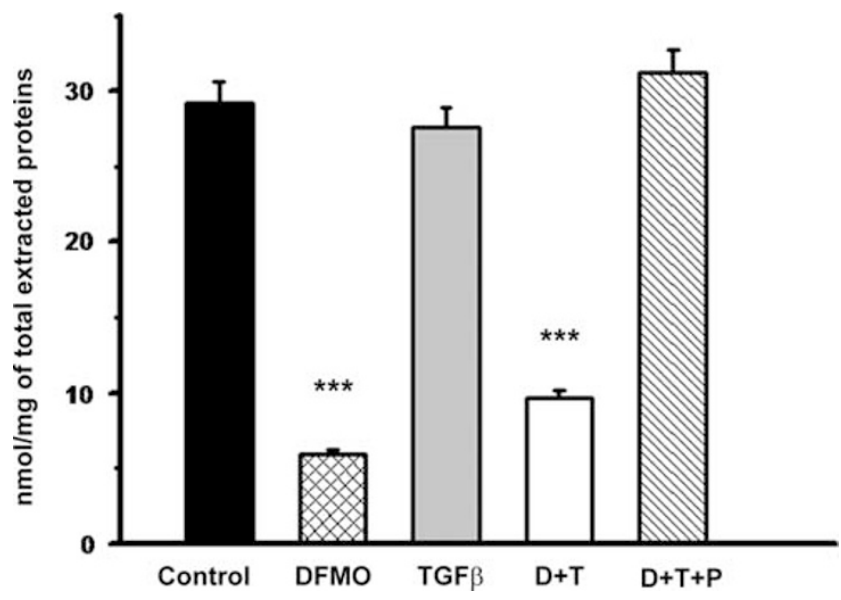

Figure 1 Bar graph showing the effect of difluoromethylornithine (DFMO), $\mathrm{TGF} \beta 1, \mathrm{DFMO}+\mathrm{TGF} \beta 1$, or DFMO $+\mathrm{TGF} \beta 1+$ administration of exogenous polyamines on total (ie including putrescine, spermidine, and spermine) intracellular polyamine levels. DFMO decreased polyamines to $\sim 20 \%$ compared with controls; TGF $\beta 1$ alone did not statistically influence polyamine content, whereas coupled administration of DFMO and TGF $\beta 1$ decreased polyamines. Exogenous polyamine addition to the culture medium restored values comparable to control. ${ }^{* *} P<0.001$ values are referred compared with control conditions.

alone did not statistically affect polyamine content, whereas combined administration of DFMO and TGF $\beta 1$ reduced intracellular polyamines to $9.635 \pm 0.482 \mathrm{nmol} / \mathrm{mg}(P<0.001$ $v s$ control value). Exogenous polyamine addition to the culture medium restored values comparable to those detected in control cells $(31.179 \pm 1.559 \mathrm{nmol} / \mathrm{mg})$.

\section{Polyamine Depletion Enhances EMT in MDCK Cells}

Polyamine-depleted MDCK cells showed a significant morphological rearrangement into large polygonal cells (Figure 2b, phase contrast panel), associated with a marked redistribution of E-cadherin staining (decreased at plasma membrane levels and increased in the cytoplasm) (Figure 2g). Immunofluorescence also showed some scattered cells exhibiting positivity for fibronectin and an increase in $\alpha$-SMA positive staining that were limited to sparse cytoplasmic rodlike structures (Figure $2 \mathrm{n}$ and s). Combined administration of DFMO and TGF $\beta_{1}$ resulted in a morphological re-arrangement at confluence (Figure 2c); very similar to the one induced by TGF $\beta_{1}$ alone. Treatment up to $96 \mathrm{~h}$ resulted in a reduced expression of the epithelial markers E-cadherin, as shown by western blot (Figure 3, panel A; Supplementary Figure 1), and ZO-1 (data not shown). Immunofluorescence analysis revealed that combined treatment resulted in the downregulation of plasma membrane E-cadherin (Figure 2i) and acquisition of a dense network of fibronectin (Figure 2p) associated to an increased expression of $\alpha$-SMA in stress fibers in each cell (Figure $2 \mathrm{u}$ ), whereas the treatment with $\operatorname{TGF} \beta_{1}$ alone resulted in an increased positive staining for $\alpha$-SMA detectable in only in 20 to $30 \%$ of cells, this feature 

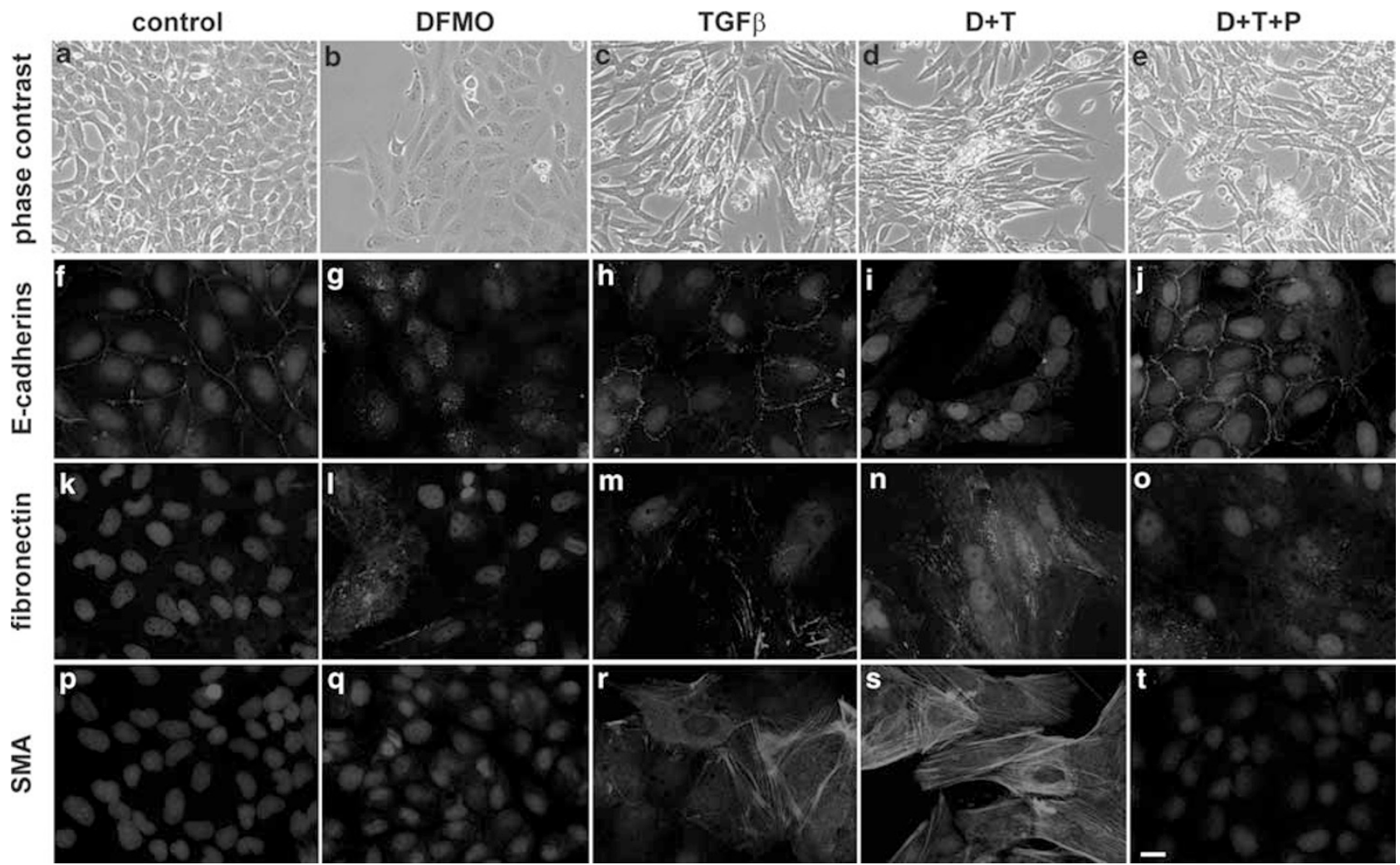

Figure 2 Phase contrast (a-e) or immunofluorescence $(\mathbf{f}-\mathbf{v})$ of MDCK cells stained for e-cadherin $(\mathbf{f}-\mathbf{l})$, fibronectin $(\mathbf{m}-\mathbf{q})$ or SMA (r-v) treated with DFMO, $\mathrm{TGF} \beta_{1}(\mathrm{TGF} \beta)$, DFMO $+\mathrm{TGF} \beta_{1}(\mathrm{D}+\mathrm{T})$, or DFMO $+\mathrm{TGF} \beta 1+$ exogenous polyamines $(\mathrm{D}+\mathrm{T}+\mathrm{P})$. MDCKs treated with $\mathrm{D}+\mathrm{T}$ showed decreased expression of e-cadherins and increased expression of fibronectin and $\alpha$-SMA compared with TGF $\beta_{1}$ alone. Polyamine addition to the medium inhibited cell phenotypical modulation induced by D T. Original magnification $200 \times(\mathbf{a}-\mathbf{e})$ and $630 \times(\mathbf{f}-\mathbf{v}$, bar $=20 \mu \mathrm{m})$.

being mainly limited to the external edge of MDCK cell islets. Exogenous polyamine addition to the medium prevented all these phenomena: E-cadherin expression on plasma membrane was maintained (Figure 2l), whereas fibronectin and $\alpha$-SMA expression was negligible (Figure $2 \mathrm{q}$ and $\mathrm{v}$, respectively). Addition of polyamines alone showed no influence on expression of all considered markers, whereas addition of polyamines to $\mathrm{TGF} \beta_{1}$ showed a moderate inhibition of $\operatorname{TGF} \beta_{1}$-stimulated phenotypical modulation (Supplementary Figure 1).

Zymograms (Figure 3, panel B) showed that polyamine depletion resulted in an increased activity of MMP2, pro-MMP9, and MMP9; moreover, polyamine depletion once again synergized with $\operatorname{TGF} \beta_{1}$ and was partially prevented by polyamine addition to the medium (ie by restoring levels similar to those observed after TGF $\beta_{1}$ alone).

\section{Polyamine Depletion Induces Limited TGF $\beta_{1}$ Secretion but not Apoptosis}

RT-PCR showed the presence of mRNA for TGF $\beta_{1}$ in control and polyamine-depleted cells (Supplementary Figure 2aA). FACS analysis of labeled cells (Supplementary Figure 2B) showed expression of TGF $\beta_{1}$ in polyamine-depleted cells equal to $5.6 \%$ of cell population whereas percentage elevated to $29.7 \%$ compared with control in the case of MDCK treated with $4.2 \mu \mathrm{M}$ Cyclosporin. TGF $\beta_{1}$ dosed in the supernatant collected at day 5 (Supplementary Figure 2C) displayed a concentration of TGF $\beta_{1}$ equal to $450 \mathrm{pg} / \mathrm{ml}$ in polyaminedepleted cells, $900 \mathrm{pg} / \mathrm{ml}$ of TGF $\beta_{1}$ in Cyclosporin-stimulated cells, whereas unstimulated control cells showed an endogenous TGF $\beta_{1}$ secretion of $90 \mathrm{pg} / \mathrm{ml}$ of TGF $\beta_{1}$. Apoptosis, assessed through Annexin V/propidium iodide labeling and subsequent FACS analysis showed no apoptosis induction in polyamine-depleted cells (Supplementary Figure 2, panel D).

\section{Proteomics}

2D proteomics showed, as expected, a great difference in the proteomic profile of TGF $\beta_{1}$ treated cells compared with controls (Figure 4, panels A and B). The proteomic profile of control, TGF $\beta_{1}$ treated, or polyamine-depleted TGF $\beta_{1}$ treated cells showed, respectively, $1584 \pm 6,1848 \pm 6$, or $1857 \pm 4$ spots. $1506 \pm 7$ spots were matched across the three groups, whereas $1847 \pm 4$ spots were matched when $\operatorname{TGF} \beta_{1}$ and polyamine-depleted $\operatorname{TGF} \beta_{1}$ treated were compared. Difference between polyamine-depleted TGF $\beta_{1}$ and TGF $\beta_{1}$ alone was limited to 30 differentially expressed spots (Figure 4, panels $\mathrm{B}$ and $\mathrm{C}$ ), among them, 27 showed a statistically significant twofold upregulation compared with $\mathrm{TGF} \beta_{1}$ alone. 
Spots were subsequently identified with LC-Mass spectrometry (see Table 1 ), $\alpha$-enolase (spots $4,5,6$ ), vimentin (spots $7,8,9$ ), glucose-regulated protein $78 \mathrm{kDa}$ (GRP78, spots 10 ,

a

E-Cadherin

Control DFMO TGF $\beta \quad D+T \quad D+T+P$

Fibronectin

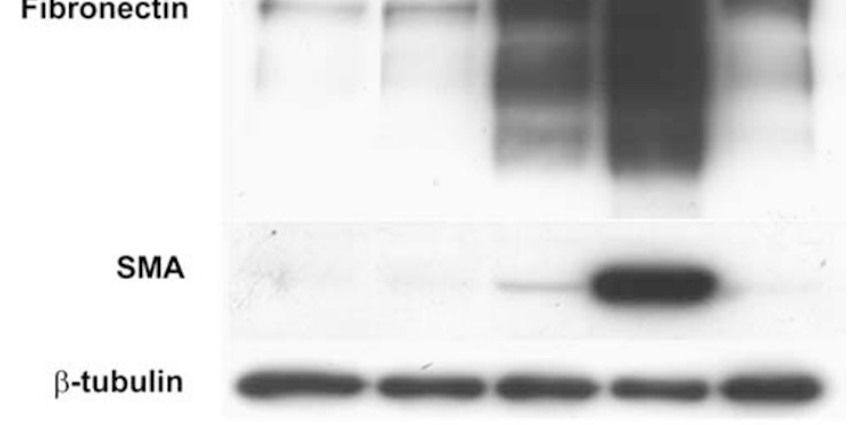

b

pro-MMP9
MMP9

MMP2

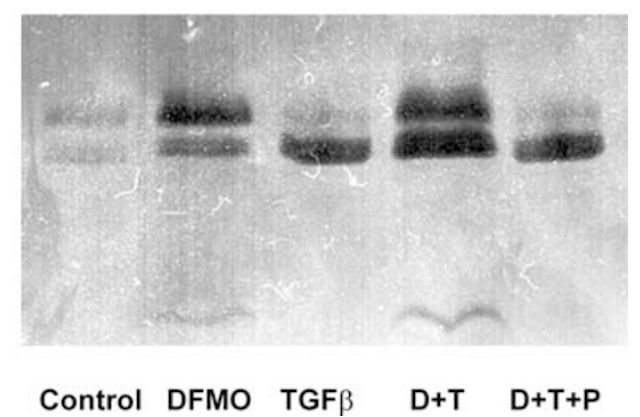

Figure 3 Representative western blot (a) or for E-cadherin, fibronectin or $\alpha$-SMA of MDCK cells treated with DFMO, TGF $\beta_{1}(\operatorname{TGF} \beta), \mathrm{DFMO}+\operatorname{TGF} \beta_{1}$ $(D+T)$, or DFMO + TGF $\beta 1+$ exogenous polyamines $(D+T+P)$.

(b) Zymogram for the same conditions. Polyamine depletion decreased epithelial marker e-cadherins and increased expression of mesenchymal markers fibronectin and SMA while at the same time increasing activity of MMP2, pro-MMP9, and MMP9. $\beta$-Tubulin was charged as loading control.
$11,12)$, glucose-regulated protein $94 \mathrm{kDa}$ (GRP94, spot 13), or HSP90 $\alpha / \beta$ (spots $16,17,18$ ).

Each gel was performed in triplicate and analyzed using PDQuest Advanced software (Bio-Rad). Average gels were created from the three gels for each type of condition. Normalization and statistical analysis of the results were then performed to compare each condition.

\section{Functional Assessment Using a Biotinilated Polyamine}

BPA was efficiently incorporated in MDCK cells as revealed by immunofluorescence (Figure 5a). Competition with exogenous polyamines reduced BPA incorporation within cells, whereas administration of a TG-2 siRNA (Figure 5c) notably decreased TG-2-dependent covalent bond formation of polyamines on cellular target proteins. BPA is thereby covalently linked only in the presence of active TG-2. Moreover, 2D blots of BPA-labeled proteins showed that BPA is covalently linked on a limited subset of cellular proteins (Figure 5b). Statistically significant twofold upregulated proteins were all $\mathrm{BPA}^{+}$. A complete list of $\mathrm{BPA}^{+}$proteins is displayed in Table 1.

\section{Silencing of TG-2 Induces upregulation of Endoplasmic Reticulum-Stress Proteins and Enhanced EMT}

Silencing of TG-2 in the presence of polyamines (Figure 6), added $4 \mathrm{~h}$ later, showed a response of cell to TGF $\beta_{1}$ quite similar to administration of $\mathrm{TGF} \beta_{1}$ in combination with DFMO. In both conditions, $\mathrm{D}+\mathrm{T}$ or TG-2 silenced cells, both GRP78 and $\alpha$-SMA were upregulated compared with $\operatorname{TGF} \beta_{1}$ alone. These evidences suggest that TG-2-dependent polyamine covalent bond formation on endoplasmic reticulum (ER)-stress proteins is a relevant post-translational modification for homeostasis of ER-stress proteins. When polyamines are depleted from cells or their covalent bond formation on ER-stress proteins is inhibited through silencing of TG-2, cells increase expression of GRP78 and GRP94 (data not shown) thereby increasing cells susceptibility to $\operatorname{TGF} \beta_{1}$.
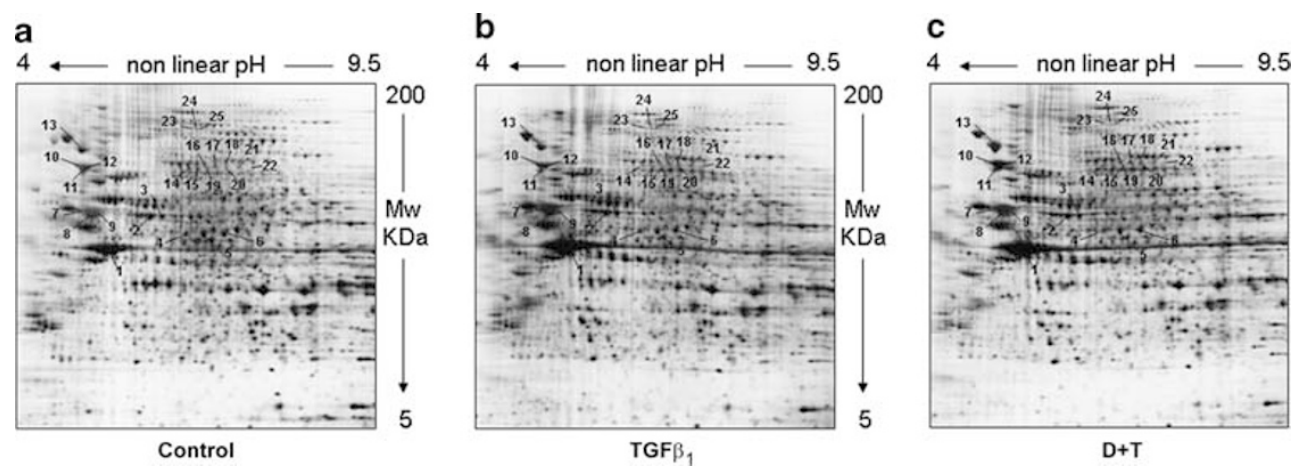

Figure 4 Silver staining of representative 2D electrophoresis showing the effect of TGF $\beta 1$ (TGF $\beta$ ) or DFMO + TGF $\beta_{1}$ (D + T) on proteomic profile of MDCK cells. (a) Untreated cells, (b) TGF $\beta$, or (c) DFMO + TGF $\beta_{1}$. Statistically differentially expressed spots between condition TGF $\beta$ and D + T were labeled with numbers. Correspondence with mass spectrometry identified proteins is reported in Table 1. 


\begin{tabular}{|c|c|c|c|c|c|c|}
\hline Spot & Proteins name & $\begin{array}{l}\text { Accession } \\
\text { number }\end{array}$ & Score & Coverage & $\begin{array}{l}\text { Unique } \\
\text { Peptide }\end{array}$ & \\
\hline 1 & $\beta$-Actin like & gi|55741585 & 294.34 & 42.90 & 30 & BPA \\
\hline 2 & Similar to Keratin, type II cytoskeletal & gi|73996455 & 300.35 & 41.00 & 30 & BPA \\
\hline 4 & Similar to $\alpha$ enolase & gi|74007151 & 180.29 & 38.00 & 18 & BPA, $2 \times$ \\
\hline 5 & Similar to $\alpha$ enolase & gi|74007151 & 184.31 & 35.30 & 19 & BPA, $2 \times$ \\
\hline 6 & Similar to $\alpha$ enolase & gi|74007151 & 214.32 & 45.30 & 22 & BPA, $2 \times$ \\
\hline 7 & Similar to vimentin isoform 1 & gi|73948956 & 320.30 & 47.90 & 32 & BPA, $2 \times$ \\
\hline 8 & Similar to vimentin isoform 1 & gi|73948956 & 386.33 & 50.00 & 39 & BPA, $2 \times$ \\
\hline 11 & Similar to 78 kDa glucose-regulated protein precursor (GRP 78) & gi|73968072 & 230.29 & 38.00 & 23 & BPA, $2 \times$ \\
\hline 12 & Similar to 78 kDa glucose-regulated protein precursor (GRP 78) & gi|73968072 & 360.32 & 55.10 & 36 & BPA, $2 \times$ \\
\hline 13 & Heat shock protein $90 \mathrm{kDa} \beta$, member $194 \mathrm{kDa}$ glucose regulate protein (GRP 94) & gi|50979166 & 270.36 & 38.10 & 27 & BPA, $2 \times$ \\
\hline 14 & Similar to Lamin A/C (70 kDa lamin) isoform 5 & gi|73960926 & 50.24 & 10.70 & 5 & BPA \\
\hline 15 & Similar to Lamin A/C (70 kDa lamin) isoform 5 & gi|73960926 & 40.19 & 6 & 4 & BPA \\
\hline \multirow[t]{2}{*}{16} & Similar to Heat shock protein HSP $90 \alpha$ & gi|73989602 & 76.24 & 19.90 & 8 & \\
\hline & Similar to heat shock protein $1, \beta$ & gi|74007237 & 66.26 & 35.70 & 7 & BPA, $2 \times$ \\
\hline \multirow[t]{2}{*}{17} & Similar to Heat shock protein HSP $90 \alpha$ & gi|73989602 & 66.22 & 17.70 & 7 & \\
\hline & Similar to heat shock protein $1, \beta$ & gi|74007237 & 48.23 & 20.60 & 5 & BPA, $2 \times$ \\
\hline 23 & Non-detected & & & & & BPA \\
\hline 24 & Non-detected & & & & & BPA \\
\hline 25 & Non-detected & & & & & BPA \\
\hline
\end{tabular}

\section{BPA Positive Protein Expression is Changed on DFMO or Polyamine Administration}

GRP78, GRP94, HSP90 $\alpha / \beta, \alpha$-enolase, or vimentin showed to be statistically upregulated in TGF $\beta_{1}$-treated cells compared with control ( $P \leq 0.05$ in all cases). GRP78, GRP94, HSP90 $\alpha$ / $\beta, \alpha$-enolase showed an upregulation in polyamine-depleted TGF $\beta_{1}$ treated cells. Exogenous polyamines addition partially restored expression levels of these proteins (Figure 7).

\section{DISCUSSION}

This study supports for the first time a major role for polyamines in EMT in MDCK cells (for review see Hay and $\mathrm{Zuk}^{29}$ ). EMT is a complex process that regulates major events during early development and, in adult life, has a pivotal function in tissue remodeling during wound healing, organ fibrosis, and cancer progression. ${ }^{2}$ Although a full comprehension of EMT is still far from being achieved, it is generally accepted that epithelial cells undergo a number of defined phenotypic and functional changes that include first loss of epithelial markers and then acquisition of mesenchymal-like traits. The final cell emerging from the EMT program expresses features distinctive of the myofibroblast, such as tensile properties, conferred by the presence of $\alpha$-SMA cytoplasmic filaments. Transformation of MDCKs to mesenchymal-like cells has been reported earlier in vitro by using antibodies to E-cadherin.

As stated above, EMT is often regarded as a process of de-differentiation in which epithelia loose their specific markers acquiring a mesenchymal phenotype. Newly 
a

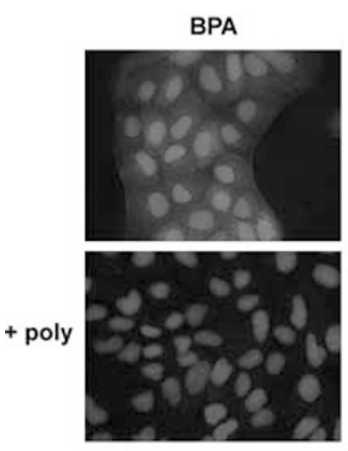

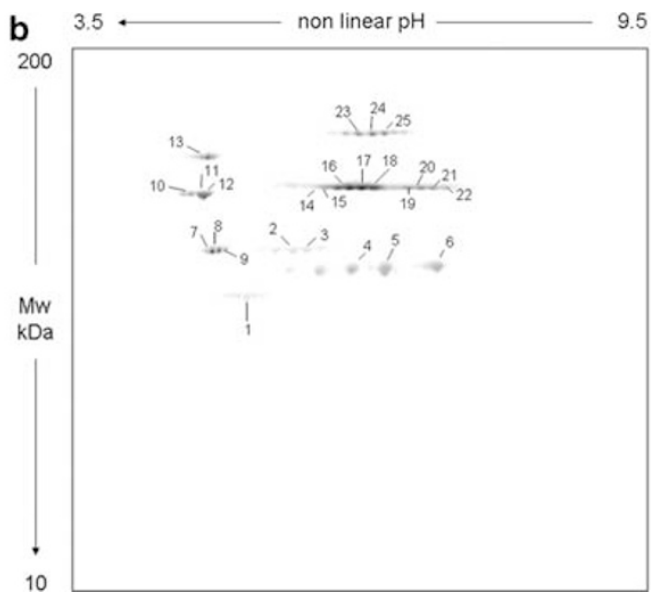

C

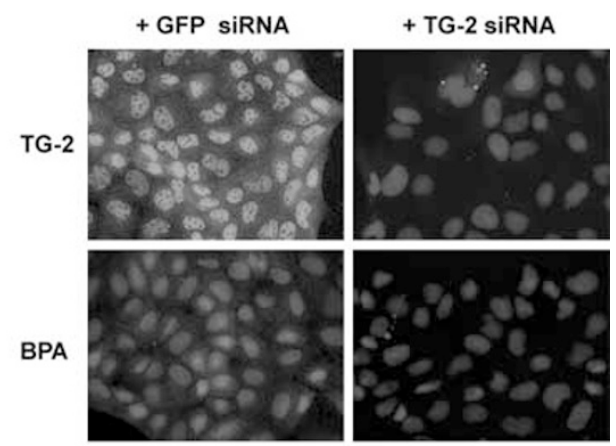

Figure 5 (a) Penthylamine-biotin (BPA) incorporation in polyamine-depleted MDCK cells or in presence of exogenous polyamines (poly) (b). BPA is actively incorporated in MDCK cells. Competition with exogenous polyamines drastically reduced BPA staining. (b) 2D blots of BPA-labeled proteins revealed with neutravidin-HRP showed incorporation of BPA on several cellular proteins, labels are reported in Table 1. (c) Transfection of siRNA designed against transglutaminase-2 (TG-2) drastically reduced TG-2 expression hence reducing BPA incorporation in MDCK cells, siRNA for GFP was administered as control.

TG-2

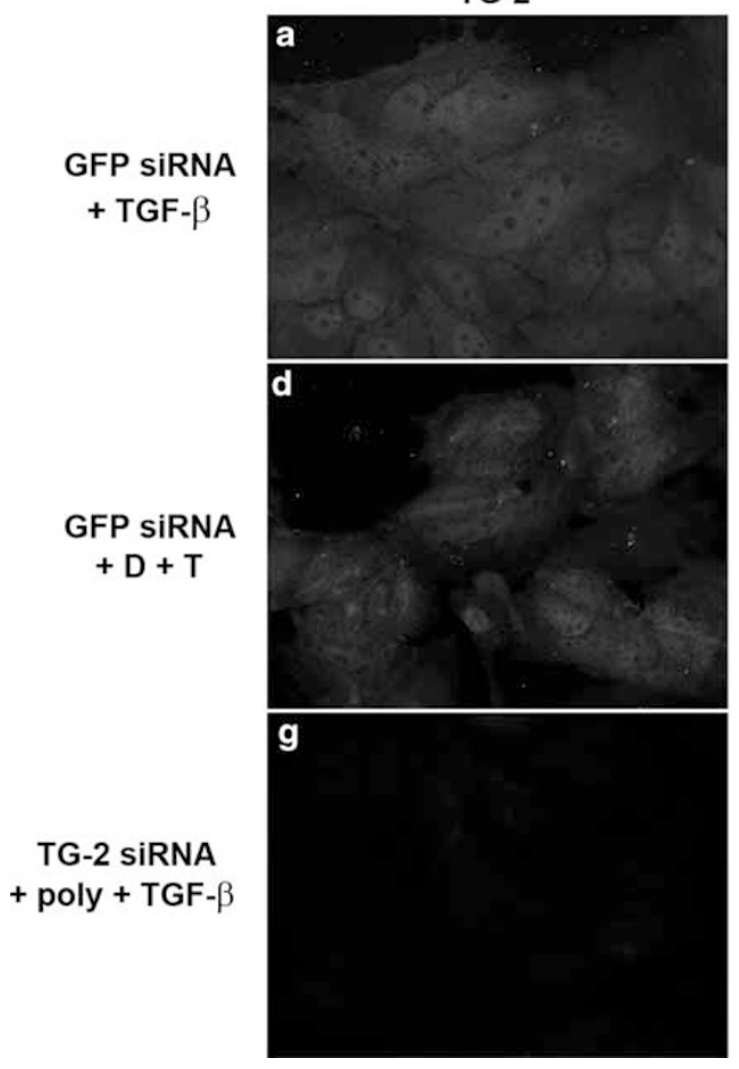

GRP78
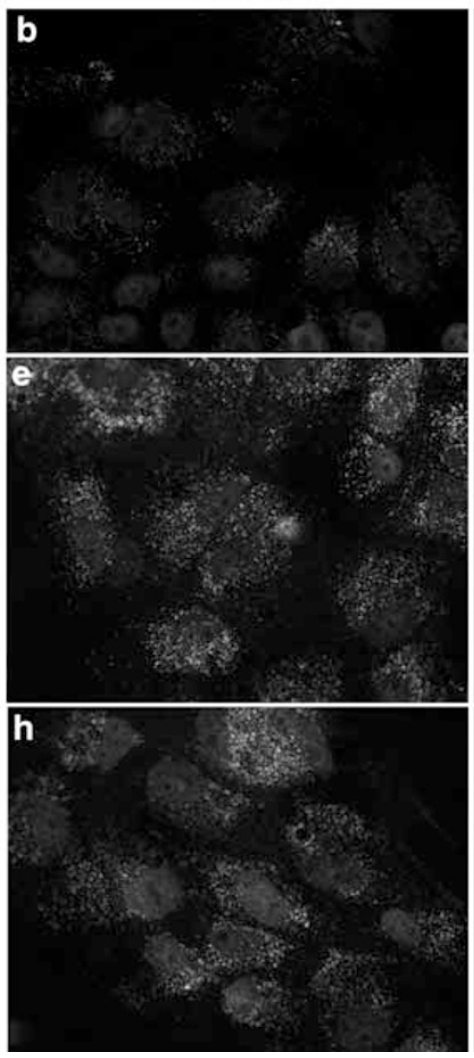

SMA
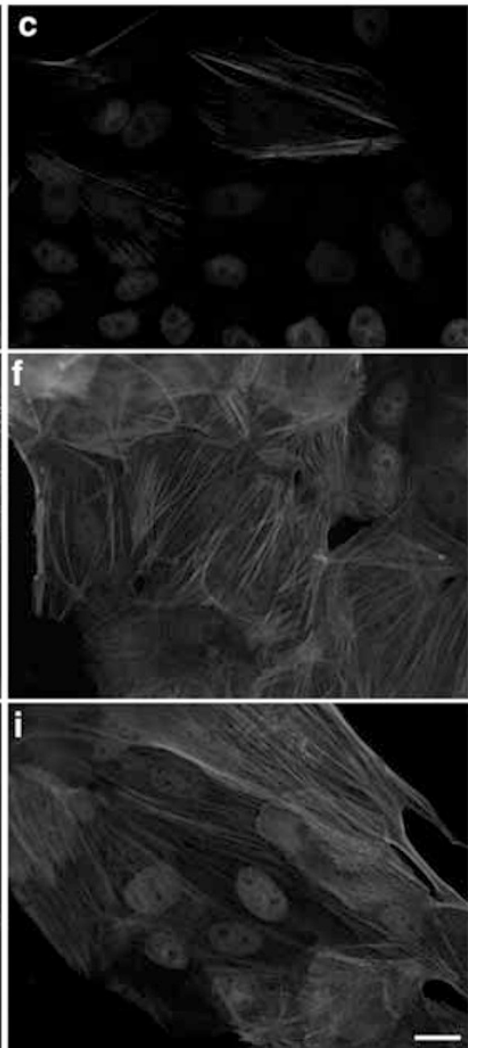

Figure 6 Silencing of TG-2 or polyamine depletion enhance EMT in MDCK cells. Cells silenced for TG-2 (g) and subsequent treated with TGF $\beta_{1}$ in the presence of polyamines showed an increased expression of GRP78 (h) and $\alpha$-SMA (i) similar to polyamine-depleted cells (in e, f, respectively) treated with control GFP siRNA (d) compared with cells treated with TGF $\beta_{1}$ alone (b and $\mathbf{c}$, respectively) and silenced with control GFP siRNA (a). GRP78 polyamination is TG-2 dependent and modulate EMT in MDCK cells. Original magnification $630 \times$, bar $=20 \mu \mathrm{m}$.

differentiated cells exhibit activation of MMPs, enzymes that cleave almost all extracellular matrix components, and activate growth factors and growth factor receptors. ${ }^{30}$
The results of this study indicate that polyamine depletion enhances TGF $\beta_{1}$-induced EMT in MDCKs by downregulating epithelial markers ZO-1 and E-cadherin as well as 


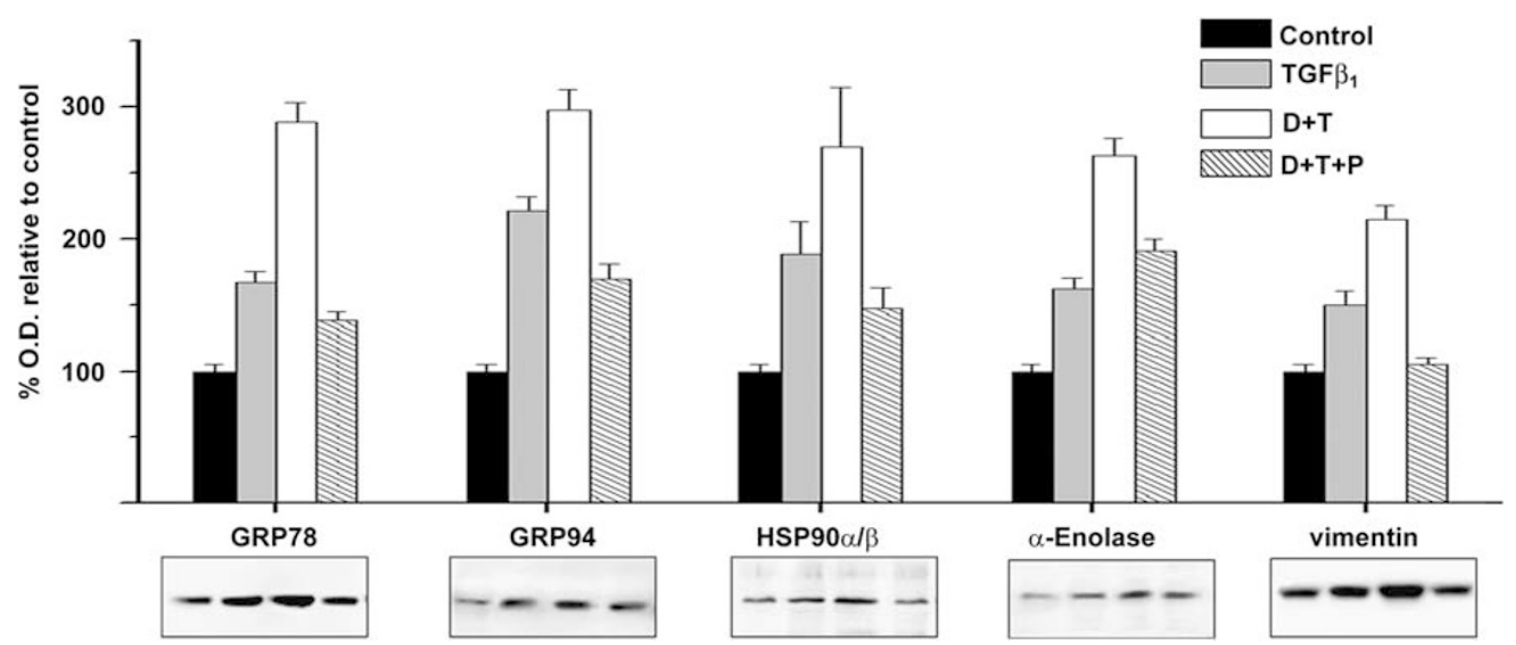

Figure 7 Representative western blots and corresponding bar graphs showing effect of TGF $\beta_{1}$, DFMO + TGF $\beta_{1}$ (D + T), or DFMO + TGF $\beta_{1}+$ exogenous polyamines $(D+T+P)$ on cellular expression of GRP78, GRP94, HSP90 $\alpha / \beta$, $\alpha$-enolase, or vimentin expression.

by increasing expression of mesenchymal markers fibronectin and $\alpha$-SMA. At the same time, polyamine depletion increases activity of MMP2, pro-MMP9, and MMP9, all enzymes involved in the break down of cell-cell and cell-ECM interactions, thus triggering EMT process. ${ }^{30-32}$ Polyamine depletion and TGF $\beta_{1}$ stimulation show a synergic effect on EMT-related markers, as also confirmed by the fact that exogenous polyamine addition, which restores intracellular polyamine content, prevents these changes. Although a limited TGF $\beta_{1}$ secretion is induced by the sole administration of DFMO, this is in any case insufficient to induce the observed enhanced EMT. Levels of TGF $\beta_{1}$ induced by DFMO are in fact the half of those induced by $4.2 \mu \mathrm{M}$ Cyclosporin administration that proved earlier ${ }^{23}$ to be capable to alter paracellular permeability but not EMT. The irrelevance of DFMO-induced TGF $\beta_{1}$ secretion allowed us to look for a possible alternative explanation for the observed enhanced EMT in polyamine-depleted cells. For this reason, a proteomic approach was applied. $2 \mathrm{D}$ proteomic analysis of TGF $\beta_{1}$-treated and polyamine-depleted MDCKs $v s$ TGF $\beta_{1}$ treated MDCKs showed a statistically significant variation of 30 spots among the two conditions: we identified enhanced expression of $\alpha$-enolase, vimentin, $\mathrm{HSP} 90 \alpha / \beta$, GRP78, and GRP94. A growing body of literature indicates an essential function for GRP78 and GRP94 proteins in preserving ER function. In particular, the $78 \mathrm{kDa}$ molecular chaperone GRP78 is ubiquitously expressed in mammalian cells, and it has been reported to bind to hydrophobic patches on nascent polypeptides in the ER. This is to prevent aggregation of misfolded proteins and to contribute to the development of proper secondary structure of mature proteins. In addition to preventing the physical aggregation of misfolded proteins, GRP78 is one of the initial components in the signaling cascade of the so-called unfolded protein response (UPR). Similarly to GRP78, GRP94, identified as a $94-\mathrm{kDa}$ protein also referred to as ERp99 $9^{33}$ or endoplasmin,${ }^{34}$ is an abundant ER glycoprotein. It shares $50 \%$ amino acid identity to HSP90 $\alpha / \beta$, a well-characterized $90-\mathrm{kDa}$ member of the heat-shock protein family. Recent evidence suggests that GRP94 may also possess protein chaperoning activity. Its synthesis is induced by the accumulation of misfolded proteins in the ER. ${ }^{35,36}$ In the ER, GRP78 and GRP94 act in tandem on folding intermediates of the newly synthesized immunoglobulin chains, with GRP94 being involved at a more advanced step in their processing. ${ }^{37}$

Upregulation of both GRP78 and GRP94, together with $\alpha$-enolase and vimentin, has been validated in our model by western blot analysis performed at day 3 after TGF $\beta_{1}$ administration. We substantially confirmed earlier immunohistochemical and electron microscopy findings by Parkkinen et al. ${ }^{38}$ These authors showed in fact redistribution, whorl formation, and autophagy of the ER in polyamine-deprived BHK cells. This is of particular interest in view of recent in vitro studies ${ }^{39,40}$ demonstrating that disturbances of the ER homeostasis results in a EMT-like process characterized by cell morphology changes and extensive reorganization of the actin cytoskeleton. ${ }^{2,39,40}$

In our model, endocellular polyamine depletion dramatically enhances TGF $\beta_{1}$-induced EMT, by increasing at the same time the expression of typical ER-stress proteins like GRP78 and GRP94, thus suggesting a direct involvement of ER-stress in the overall and polyamine depletion-dependent scenario.

Preliminary experiments, performed with a rat hepatoma cell line (HTC) clonally selected to be defective for polyamine transport across cell membrane (data not shown, manuscript in preparation), show that endocellular polyamine availability is crucial. In these mutant cells, exogenous polyamines are ineffective in counteracting induction of fibronectin by 
combined DFMO and TGF $\beta_{1}$ treatment, thus excluding a direct effect of polyamines on TGF $\beta_{1}$ binding on its receptor.

Results of the experiments performed by loading MDCKs with a biotin-linked cadaverine (BPA), in the presence or in the absence of DFMO, suggest that polyamines might be directly involved in the regulation of both GRP78 and GRP94. BPA, that is a mono-functional polyamine carrying only one free $-\mathrm{NH}_{2}$ function, is efficiently up taken by MDCK cells, as demonstrated by immunofluorescence. Within the cell, BPA is than covalently linked to a specific and limited number of cellular proteins. These experiments revealed GRP78 and GRP94 as putative protein targets for polyamine covalent bond formation.

Availability of endocellular polyamines is thereby critical for the regulation of GRP78 and GRP94 and, possibly, for the regulation of ER-stress and subsequent induction of an EMTlike process. Results showed that cell response to TGF $\beta_{1}$ demonstrated to be very similar in polyamine-depleted cells as well as in cells where TG-2 was previously silenced in the presence of polyamines. In all cells, both ER-stress protein GRP7 8 and $\alpha$-SMA were upregulated compared with TGF $\beta_{1}$ alone, suggesting that polyamination, through covalent bond formation induced by TG-2, may be a relevant post-translational modification for ER-stress proteins homeostasis. In our experimental settings, TG-2-dependent polyamine covalent bond formation onto ER-stress proteins may represent an intracellular regulatory mechanism able to counteract TGF $\beta_{1}$ induced EMT. In this respect, it is noteworthy that a recent in vivo study has reported that TG-2 inhibition ameliorates experimental fibrosis. ${ }^{41}$ Moreover, further studies are needed to fully comprehend relevance of polyamine biology in the cell, in particular related to TGF $\beta_{1}$ pathway. Moderate inhibition of TGF $\beta_{1}$-stimulated phenotypical modulation by the sole addition of polyamines, suggests in fact involvement of polyamines also in other cellular pathways.

In conclusion, our work provides the first evidence for a key role of polyamines in EMT. 2D proteomic approach allowed suggesting a direct link between polyamine depletion, activation of ER-stress, and enhancement of EMT, thus reinforcing the concept that ER-stress may be crucial for the epithelial cell fate and the triggering of an EMT-like response.

Supplementary Information accompanies the paper on the Laboratory Investigation website (http://www.laboratoryinvestigation.org)

\section{ACKNOWLEDGEMENT}

We acknowledge the RenalChild Foundation for the financial support and Professor Rosanna Gusmano for critical discussion of results.

1. Radisky DC, Kenny PA, Bissell MJ. Fibrosis and cancer: do myofibroblasts come also from epithelial cells via EMT? J Cell Biochem 2007;101:830-839.

2. Thiery JP, Sleeman JP. Complex networks orchestrate epithelialmesenchymal transitions. Nat Rev Mol Cell Biol 2006;7:131-142.

3. McAnulty RJ. Fibroblasts and myofibroblasts: their source, function and role in disease. Int J Biochem Cell Biol 2007;39:666-671.
4. Nishikawa Y, Kar S, Wiest L, et al. Inhibition of spermidine synthase gene expression by transforming growth factor-beta 1 in hepatoma cells. Biochem J 1997;321(Pt 2):537-543.

5. Stabellini G, Moscheni C, Gagliano N, et al. Depletion of polyamines and increase of transforming growth factor-beta1, c-myc, collagentype I, matrix metalloproteinase-1, and metalloproteinase-2 mRNA in primary human gingival fibroblasts. J Periodontol 2005;76:443-449.

6. Barnes RN, Bungay PJ, Elliott BM, et al. Alterations in the distribution and activity of transglutaminase during tumour growth and metastasis. Carcinogenesis 1985;6:459-463.

7. Birckbichler PJ, Orr GR, Patterson Jr MK. Differential transglutaminase distribution in normal rat liver and rat hepatoma. Cancer Res 1976;36:2911-2914.

8. Birckbichler PJ, Patterson Jr MK. Cellular transglutaminase, growth, and transformation. Ann NY Acad Sci 1978;312:354-365.

9. Pegg $A E$. Recent advances in the biochemistry of polyamines in eukaryotes. Biochem J 1986;234:249-262.

10. Kannagi R, Teshigawara K, Noro N, et al. Transglutaminase activity during the differentiation of macrophages. Biochem Biophys Res Commun 1982;105:164-171.

11. Tabor CW, Tabor H. Polyamines. Annu Rev Biochem 1984;53:749-790.

12. Gentile V, Thomazy V, Piacentini $M$, et al. Expression of tissue transglutaminase in Balb-C 3 T3 fibroblasts: effects on cellular morphology and adhesion. J Cell Biol 1992;119:463-474.

13. Oliverio S, Amendola A, Di Sano F, et al. Tissue transglutaminasedependent posttranslational modification of the retinoblastoma gene product in promonocytic cells undergoing apoptosis. Mol Cell Biol 1997; 17:6040-6048.

14. Koenig $\mathrm{H}$, Goldstone AD, Lu CY. Beta-adrenergic stimulation of $\mathrm{Ca} 2+$ fluxes, endocytosis, hexose transport, and amino acid transport in mouse kidney cortex is mediated by polyamine synthesis. Proc Natl Acad Sci USA 1983;80:7210-7214.

15. Koenig $\mathrm{H}$, Goldstone $A D$, Lu CY. Polyamines are intracellular messengers in the beta-adrenergic regulation of $\mathrm{Ca} 2+$ fluxes, [Ca2+]i and membrane transport in rat heart myocytes. Biochem Biophys Res Commun 1988;153:1179-1185.

16. Kohno H, Sasaki K, Yamaguchi M, et al. Spermine modulates calcium flux through the rat erythrocyte membrane. Biol Pharm Bull 1997;20:153-157.

17. Kameji T, Pegg AE. Inhibition of translation of mRNAs for ornithine decarboxylase and S-adenosylmethionine decarboxylase by polyamines. J Biol Chem 1987;262:2427-2430.

18. Heby O, Persson L, Rentala M. Targeting the polyamine biosynthetic enzymes: a promising approach to therapy of African sleeping sickness, Chagas' disease, and leishmaniasis. Amino Acids 2007;33:359-366.

19. Gerner EW, Meyskens Jr FL, Goldschmid S, et al. Rationale for, and design of, a clinical trial targeting polyamine metabolism for colon cancer chemoprevention. Amino Acids 2007;33:189-195.

20. Meyskens Jr FL, Gerner EW. Development of difluoromethylornithine (DFMO) as a chemoprevention agent. Clin Cancer Res 1999;5: 945-951.

21. Lentini A, Abbruzzese A, Caraglia $M$, et al. Protein-polyamine conjugation by transglutaminase in cancer cell differentiation: review article. Amino Acids 2004;26:331-337.

22. Baydoun AR, Morgan DM. Inhibition of ornithine decarboxylase potentiates nitric oxide production in LPS-activated J774 cells. Br J Pharmacol 1998;125:1511-1516.

23. Feldman G, Kiely B, Martin N, et al. Role for TGF-beta in cyclosporineinduced modulation of renal epithelial barrier function. J Am Soc Nephrol 2007;18:1662-1671.

24. Colombatto S, Fasulo L, Fulgosi B, et al. Transport and metabolism of polyamines in human lymphocytes. Int J Biochem 1990;22:489-492.

25. Bruschi M, Musante L, Candiano G, et al. Soft immobilized pH gradient gels in proteome analysis: a follow-up. Proteomics 2003;3:821-825.

26. Candiano $G$, Bruschi $M$, Musante $L$, et al. Blue silver: a very sensitive colloidal Coomassie G-250 staining for proteome analysis. Electrophoresis 2004;25:1327-1333.

27. Adamski M, Blackwell $T$, Menon $R$, et al. Data management and preliminary data analysis in the pilot phase of the HUPO Plasma Proteome Project. Proteomics 2005;5:3246-3261.

28. Brisset $A C$, Hao $H$, Camenzind $E$, et al. Intimal smooth muscle cells of porcine and human coronary artery express S100A4, a marker of the rhomboid phenotype in vitro. Circ Res 2007;100:1055-1062. 
29. Hay ED, Zuk A. Transformations between epithelium and mesenchyme: normal, pathological, and experimentally induced. Am J Kidney Dis 1995;26:678-690.

30. Sternlicht MD, Werb Z. How matrix metalloproteinases regulate cell behavior. Annu Rev Cell Dev Biol 2001;17:463-516.

31. Cicchini C, Laudadio I, Citarella F, et al. TGFbeta-induced EMT requires focal adhesion kinase (FAK) signaling. Exp Cell Res 2008;314:143-152.

32. Hojilla CV, Mohammed FF, Khokha R. Matrix metalloproteinases and their tissue inhibitors direct cell fate during cancer development. Br J Cancer 2003;89:1817-1821.

33. Mazzarella RA, Green M. ERp99, an abundant, conserved glycoprotein of the endoplasmic reticulum, is homologous to the $90-\mathrm{kDa}$ heat shock protein (hsp90) and the 94-kDa glucose regulated protein (GRP94). J Biol Chem 1987;262:8875-8883.

34. Koch G, Smith M, Macer D, et al. Endoplasmic reticulum contains a common, abundant calcium-binding glycoprotein, endoplasmin. J Cell Sci 1986;86:217-232.

35. Kim YK, Kim KS, Lee AS. Regulation of the glucose-regulated protein genes by beta-mercaptoethanol requires de novo protein synthesis and correlates with inhibition of protein glycosylation. J Cell Physiol 1987;133:553-559.
36. Kozutsumi $Y$, Segal M, Normington K, et al. The presence of malfolded proteins in the endoplasmic reticulum signals the induction of glucose-regulated proteins. Nature 1988;332: 462-464.

37. Melnick J, Aviel S, Argon Y. The endoplasmic reticulum stress protein GRP94, in addition to BiP, associates with unassembled immunoglobulin chains. J Biol Chem 1992;267:21303-21306.

38. Parkkinen JJ, Lammi MJ, Agren U, et al. Polyamine-dependent alterations in the structure of microfilaments, Golgi apparatus, endoplasmic reticulum, and proteoglycan synthesis in BHK cells. J Cell Biochem 1997;66:165-174.

39. Ulianich L, Garbi C, Treglia AS, et al. ER stress is associated with dedifferentiation and an epithelial-to-mesenchymal transition-like phenotype in PC Cl3 thyroid cells. J Cell Sci 2008;121(Pt 4): 477-486.

40. Seki K, Fujimori T, Savagner $P$, et al. Mouse Snail family transcription repressors regulate chondrocyte, extracellular matrix, type II collagen, and aggrecan. J Biol Chem 2003;278:41862-41870.

41. Ishii Y, Ichikawa M, Yamaguchi K, et al. Localization of cephalosporinase in Enterobacter cloacae by immunocytochemical examination. J Antibiot (Tokyo) 1991;44:1088-1095. 